\title{
Atypical presentations of neuromyelitis optica
}

\author{
Douglas Sato ${ }^{1,2}$, Kazuo Fujihara ${ }^{3}$
}

\begin{abstract}
Neuromyelitis optica (NMO) is an inflammatory disease of central nervous system classically characterized by acute, severe episodes of optic neuritis and longitudinally extensive transverse myelitis, usually with a relapsing course. The identification of an autoantibody exclusively detected in NMO patients against aquaporin-4 (AQP-4) has allowed identification of cases beyond the classical phenotype. Brain lesions, once thought as infrequent, can be observed in NMO patients, but lesions have different characteristics from the ones seen in multiple sclerosis. Additionally, some AQP-4 antibody positive patients may present with a variety of symptoms not being restricted to optic neuritis and acute myelitis during the first attack or in a relapse. Examples are not limited to, but may include patients only with brain and/or brainstem lesions, narcolepsy with hypothalamic lesions or patients with intractable hiccups, nausea and vomiting. The prompt identification of NMO patients with atypical presentations may benefit these patients with institution of early treatment to reduce disability and prevent further attacks.
\end{abstract}

Key words: neuromyelitis optica, aquaporin 4, myelitis, optic neuritis, diagnosis, differential, nausea, vomiting, hiccup, brain diseases.

\section{Apresentações atípicas da neuromielite óptica}

\section{RESUMO}

Neuromielite óptica (NMO) é uma doença inflamatória do sistema nervoso central caracterizada classicamente por neurite óptica grave e mielite transversa longitudinalmente extensa, com um curso usualmente recorrente. A identificação do anticorpo detectado exclusivamente nos pacientes com NMO contra a aquaporina-4 (AQP-4) permitiu a identificação de casos além do fenótipo clássico. Lesões cerebrais, que antes eram descritas como infrequentes, podem ser observadas em pacientes com NMO, mas as lesões possuem características diferentes das lesões observadas na esclerose múltipla. Além disso, alguns pacientes positivos para o anticorpo contra a AQP-4 podem apresentar uma variedade de sintomas não restritos à neurite óptica e mielite aguda, seja durante o primeiro ataque seja em uma recorrência. Exemplos não estão limitados aos descritos a seguir, mas incluem pacientes com lesões cerebrais e/ou tronco cerebral, narcolepsia com lesões hipotalâmicas ou pacientes com quadros intratáveis de soluços, náusea e vômitos. A identificação rápida dos pacientes com NMO com apresentações atípicas pode beneficiar estes pacientes com a instituição precoce do tratamento a fim de reduzir a incapacidade e prevenir ataques subsequentes.

Palavras-Chave: neuromielite óptica, aquaporina 4, mielite, neurite óptica, diagnóstico diferencial, náusea, vômito, soluço, encefalopatias.

\section{Correspondence}

Douglas K. Sato

Department of Neurology

Tohoku University Graduate

School of Medicine

1-1, Seiryomachi, Aobaku Sendai,

Miyagi, 980-8574, Japan

E-mail: douglas.sato@med.tohoku.ac.jp

Received 18 August 2011

Accepted 26 August 2011
Neuromyelitis optica (NMO) or Devic's disease is an inflammatory disease of central nervous system classically characterized by acute, severe episodes of optic neuritis $(\mathrm{ON})$ and longitudinally extensive transverse myelitis $(\mathrm{TM})^{1}$. The article published in 1894 by Dr Eugène Devic was based on a 45 -years old female pa- 
tient presenting with bilateral ON followed by TM and she deceased about a month after the monophasic opticomyelitis ${ }^{2}$. Further studies with NMO cohorts revealed that majority of NMO patients have a relapsing disease course $^{1-4}$.

NMO has often been classified as a demyelinating disease, which includes multiple sclerosis (MS). However, unique clinical and laboratory features found in NMO patients like poor functional recovery and rare chronic progression, relatively common involvement of optic chiasm, spinal cord lesions longitudinally extending over three or more vertebral segments, absence of oligoclonal immunoglobulin G (IgG) bands, and prominent elevation of glial fibrillary acidic protein (GFAP) levels in the cerebrospinal fluids differentiate NMO patients from other demyelinating diseases. Additionally, pathological findings in NMO patients like perivascular deposition of immunoglobulins and complement, severe astrocytic damage (demonstrated by loss of AQP-4 and GFAP stainings) and a relative preservation of myelin strongly suggest that $\mathrm{NMO}$ is a clinical entity distinct from $\mathrm{MS}^{5,6}$.

The identification of an autoantibody exclusively detected in NMO patients against aquaporin-4 (AQP-4) a water channel richly expressed in the end-feet of astrocytes $^{8}$ (AQP-4 antibody, also known as NMO-IgG) provided an opportunity for a significant progress on understanding the molecular mechanisms behind NMO pathology. Among others, the demonstration in animal models ${ }^{9,10}$ (induction of transfer experimental autoimmune encephalomyelitis accompanied by the administration of immunoglobulins from AQP-4 antibody positive patients) that AQP-4 antibody activates complement, induces astrocytic damage and other features of NMO lesions, with a relative preservation of myelin basic protein staining as previously reported in pathological studies with NMO patients has provided evidence in vivo that $\mathrm{AQP}-4$ antibody is pathogenic in the presence of $\mathrm{T}$ cellmediated brain inflammation.
Since 2004, the availability for AQP-4 antibody assay at some laboratories has allowed identification of cases beyond the classical phenotype with a diversity of central nervous system (CNS) lesions ${ }^{11}$. What was once believed as atypical may be part of a common phenotype after some accumulated experience under the availability of AQP-4 antibody testing and may prompt physicians to investigate the presence of AQP-4 antibody in these patients further beyond the classical NMO phenotype.

\section{What is typical for NMO?}

The definition of typical NMO phenotype could be illustrated according to Wingerchuk's revised diagnostic criteria (2006) $)^{12}$ as patients with ON, acute myelitis, and at least two of the following three supportive criteria: [1] longitudinally extensive spinal cord lesions contiguous over three or more vertebral segments; [2] lack of brain lesions in the magnetic resonance imaging (MRI) fulfilling MS criteria at disease onset and [3] serum positivity for AQP-4 antibody. From the accumulated publications about NMO, it seems that the most common phenotype observed in the clinical practice has attacks of $\mathrm{ON}$ and TM, frequently associated with severe disability reflected clinically as severe visual deficit, paraparesis or tetraparesis with sensory level and sphincter disturbances. The clinical and laboratory findings in NMO are summarized in the Table.

As compared with Wingerchuk's original diagnostic criteria of NMO $(1999)^{1}$, the revised diagnostic criteria ${ }^{12}$ has incorporated three major changes: it included AQP-4 antibody as a supportive criterion, allowed brain lesions atypical for MS at disease onset and excluded the restriction of lesions to the optic nerve and spinal cord (about $15 \%$ of NMO patients had extra-optic-spinal CNS symptoms). As the revised diagnostic criteria is stringent in order to provide a high specificity, the concept of NMO spectrum disorders was also proposed, which included limited forms of NMO (monophasic or recurrent lon-

Table. Summary of clinical and laboratory findings in NMO patients.

\begin{tabular}{lll}
\hline Typical features & Not typical, but commonly reported & Uncommon, observed in few patients \\
\hline $\begin{array}{l}\text { Unilateral or bilateral ON with severe } \\
\text { visual impairment }\end{array}$ & $\begin{array}{l}\text { Brain lesions in the hypothalamus, corpus } \\
\text { callosum, periventricular area and brain- }\end{array}$ & $\begin{array}{l}\text { Hypersomnia, associated with bilateral } \\
\text { hypothalamic lesions and low CSF hypo- } \\
\text { cretin-1 levels } \\
\text { tem. Lesions usually have distinct fea- } \\
\text { tures of MS lesions }\end{array}$ \\
$\begin{array}{ll}\text { TM with longitudinally extensive } \\
\text { Intractable hiccups, nausea and vom- }\end{array}$ & iting, often lasting for over 48 hours \\
& Transient asymptomatic elevation of CK \\
& levels; observed few weeks prior to a & \\
& NMO attack \\
AQP-4 antibody positivity in the serum & Painful tonic spasm in the TM recovery & \\
& period & \\
\hline
\end{tabular}

ON: optic neuritis; TM: transverse myelitis; VS: vertebral segments; AQP-4: aquaporin-4; CSF: cerebrospinal fluid; CK: creatine phosphokinase. 
gitudinally extensive myelitis with three or more vertebral segment MRI spinal cord lesions, and recurrent or simultaneous bilateral $\mathrm{ON}$ ), ON or myelitis associated with "typical" NMO brain lesions like hypothalamic, callosal, periventricular and brainstem lesions, ON or longitudinally extensive myelitis associated with systemic auto-immune diseases and so-called Asian opticospinal $\mathrm{MS}^{12,13}$. However, the definition of NMO spectrum disorders did not cover patients with AQP-4 antibody positivity without $\mathrm{ON}$ and longitudinally extensive myelitis attacks, like AQP-4 antibody seropositive patients presenting only with brain or brainstem symptoms.

\section{What is not typical, but frequent in NMO}

A number of lesion sites beyond optic nerve and spinal cord have been described in NMO. Below, we review each of these "atypical" features reported in NMO patients.

\section{Brain lesions}

The initial description of NMO was a patient only with $\mathrm{ON}$ and TM, with pathological demonstration of lesions also restricted to these two sites ${ }^{2}$, and the occurrence of brain lesions in NMO had been thought as infrequent. This concept has been retained until recently, as the original criteria proposed in 1999 excluded patients with symptoms implicating other CNS regions than optic nerve and spinal cord, and required brain MRI at onset being normal or not fulfilling Paty criteria ${ }^{1}$. As described earlier, the revised criteria considered patients with brain symptoms and those not meeting Paty criteria at disease onset, but $\mathrm{ON}$ and acute myelitis remained $\mathrm{ab}$ solute in the NMO diagnostic criteria. Thus, AQP-4 antibody-positive cases with brain symptoms in the absence of $\mathrm{ON}$ and acute myelitis were beyond the scope of the revised criteria.

Since AQP-4 antibody assays have become widely available as a clinical test, the percentage of AQP-4 antibody-positive patients with brain lesions has ranged from 60 to $79 \%$ of patients ${ }^{14,15}$. Moreover, some of the

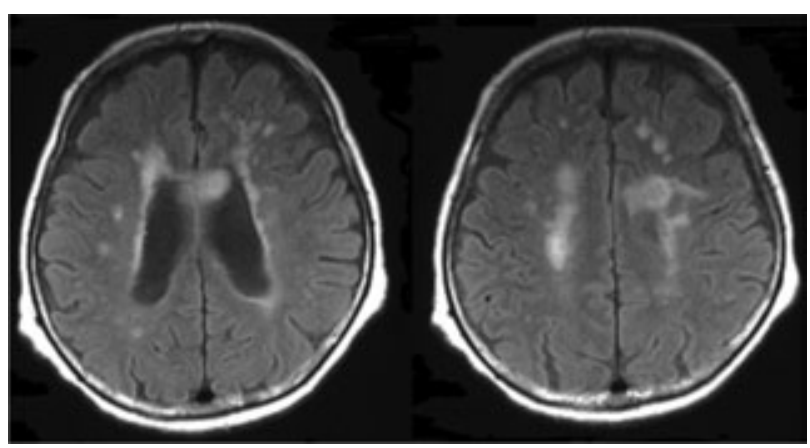

Fig 1. MRI Brain lesions in a patient with NMO. The initial symptom of this attack was apathy and right lower limb paresis. brain lesions seen in NMO are atypical for MS, such as those as longitudinally extensive brain lesions, extensive hemispheric lesions, resembling acute disseminated encephalomyelitis or posterior reversible encephalopathy syndrome, periventricular lesions and brainstem lesions often contiguous with longitudinally extensive cervical cord lesions ${ }^{15}$. Another group has reported multiple patchy gadolinium enhancing lesions with blurred margin, described as "cloud-like enhancement" in the brain MRI of NMO patients ${ }^{16}$. It is also remarkable that many of these lesion sites correspond with the regions with high expression of AQP- $4^{17}$. Fig 1 illustrates MRI brain lesions in a NMO patient.

\section{Callosal lesions}

Although callosal lesions are part of brain lesions seen in NMO, they have characteristics that help differentiate them from the ones usually seen in MS. Callosal lesions detected in NMO patients with brain symptoms often have acute features such as contrast enhancement and diffusion restriction ${ }^{14}$. Those acute lesions are usually large, multiple, and edematous with heterogeneous intensity described as a "marbled pattern". Additionally, they can involve both anterior and posterior portions of the corpus callosum and extend into both cerebral hemispheres. Fig 2 shows a MRI from a NMO patient with acute callosal lesions. In the chronic stage, these callosal lesions observed in NMO patients frequently shrink or disappear. These findings in NMO clearly differ from those of callosal lesions in MS, which are much smaller, often located at the callosal-septal interface in the middle and posterior thirds of the corpus callosum, and asymmetrical in the coronal sections.

\section{Hiccups, nausea and vomiting}

Intractable hiccup and nausea lasting over 48 hours seem to be a common feature in NMO. In our review of 144 cases of NMO spectrum disorders, 30 patients (21\%) had hiccups and 24 (17\%) had nausea ${ }^{18}$. In another study,

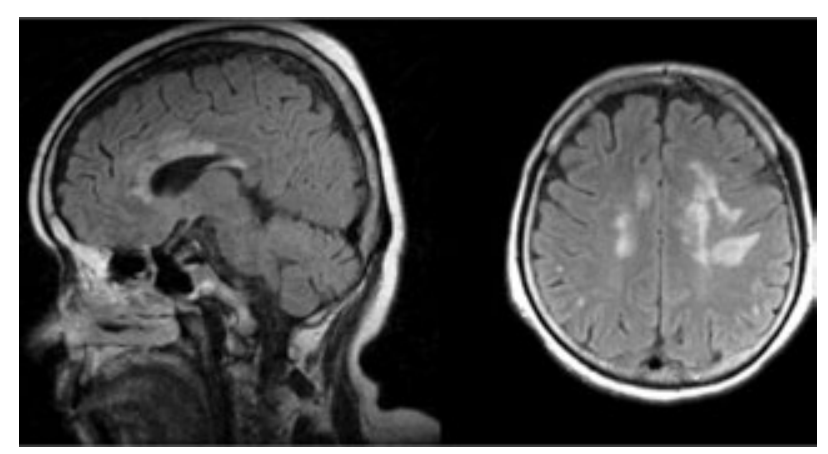

Fig 2. MRI callosal lesions with extension to the left white matter in NMO. The patient presented with acute confusional state and right hemiparesis. 


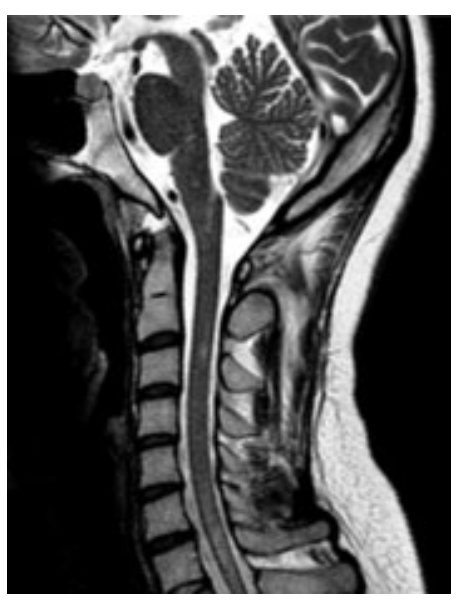

Fig 3. MRI linear medullary lesion (includes area postrema) associated with an acute attack of intractable hiccups observed in a NMO patient at hospital admission.

nearly a fifth of NMO patients presented with these symptoms whereas none of MS patients had reported such complains ${ }^{19}$. The episodes resolved spontaneously or with methylprednisolone treatment. In most cases, brain MRI on sagittal planes detected linear medullary lesions located in the periaqueductal region including the area postrema, a putative vomiting center, and the nucleus tractus solitarius. These medullary lesions, together with long and centrally located myelitis are likely to be another characteristic feature of NMO spectrum disorders. Fig 3 demonstrates a MRI linear medullary lesion associated with intractable hiccups observed in a NMO patient.

Another study characterized the neuropathological features of NMO patients with intractable nausea and vomiting ${ }^{20}$. Forty percent of these patients exhibited unilateral or bilateral lesions involving the area postrema and the medullary floor of the fourth ventricle, and those lesions had pathological features previously reported in spinal cord pathology of NMO including loss of AQP-4 staining, preservation of myelin, and complement deposition. However, unlike spinal cord lesions in NMO, GFAP staining was retained in the medullary lesions, suggesting a milder involvement.

\section{Painful tonic spasm}

Painful tonic spasm is paroxysmal tonic muscle contraction affecting one or more limbs that lasts less than a minute, and often occurs in severe myelopathy of NMO. The movement of the affected limbs usually triggers the painful tonic spasm. In our retrospective study of $37 \mathrm{pa}-$ tients with NMO and 68 patients with MS, 43\% of patients with NMO experienced painful tonic spasm while only $10 \%$ had the symptom in the MS group ${ }^{21}$. Painful tonic spasm in NMO was more frequent and uncomfortable than that in MS and required drug treatment more frequently. Painful tonic spasm is usually responsive to treatment with antiepileptic drugs like carbamazepine administered in low doses, so the early diagnosis is important for a proper management.

\section{Uncommon clinical presentations in NMO}

Hypersomnia - Excessive daytime sleepiness has been reported as a symptom of NMO spectrum disorder, associated with low levels of hypocretin-1, a hypothalamic neuropeptide for sleep-wake regulation, in the cerebrospinal fluids as seen in narcolepsy ${ }^{22,23}$. Nocturnal polysomnography and multiple sleep latency test revealed that our patient's sleep latency was less than ten minutes with sleep onset REM periods and the total sleep time was over nine hours. The symptom is caused by bilateral hypothalamic lesions, and may resolve spontaneously or shows a good response to corticosteroids treatment. This symptom can also be the first episode / attack of NMO spectrum disorder.

HyperCKemia episodes - In our retrospective study with 736 AQP-4 antibody positive patients, three patients (0.4\%) with $\mathrm{NMO}$ had prominent elevation of CK levels $(12.520,19.415$, and $59.660 \mathrm{IU} / \mathrm{L})$ associated with general fatigue a few weeks before the onset of $\mathrm{ON}^{24}$. Elevated $\mathrm{CK}$ levels resolved without any treatment in all patients, but recurred once in one of them. Although skeletal muscles express AQP-4 and this transitory elevation of CK levels may be immune-mediated, induce or stimulate AQP-4 autoimmunity, the direct relationship with AQP-4 antibody is still to be confirmed. Milder elevation on CK levels could be more common but unnoticed, and further studies are needed.

Final remarks - NMO patients may present a broader spectrum of symptoms than previously described in the classical descriptions. Further studies with large NMO cohorts may confirm the accumulated knowledge on case series studies and find additional "atypical" features of NMO spectrum disorders. It is important to be aware that patients with NMO spectrum disorders may have an initial symptom outside of optic nerve and spinal cord, such as brain and brainstem attacks. Early treatment may reduce the number of further attacks and provide benefit to these patients.

ACKNOWLEDGMENTS - We would like to thank Dr Dagoberto Callegaro, University of São Paulo, for helpful comments on the manuscript.

\section{REFERENCES}

1. Wingerchuk DM, Hogancamp WF, O'Brien PC, Weinshenker BG. The clinical course of neuromyelitis optica (Devic's syndrome). Neurology 1999;53: 1107-1114.

2. Miyazawa I, Fujihara K, Itoyama Y. Eugène Devic (1858-1930). J Neurol 2002;249:351-352

3. Collongues $\mathrm{N}$, Marignier $\mathrm{R}$, Zephir $\mathrm{H}$, et al. Neuromyelitis optica in France: a multicenter study of 125 patients. Neurology 2010;74:736-742.

4. Adoni T, Lino AM, da Gama PD, et al. Recurrent neuromyelitis optica in Brazilian patients: clinical, immunological, and neuroimaging characteristics. Mult Scler 2010;16:81-86. 
5. Takano R, Misu T, Takahashi T, Sato S, Fujihara K, Itoyama Y. Astrocytic damage is far more severe than demyelination in NMO: a clinical CSF biomarker study. Neurology 2010;75:208-216.

6. Misu T, Fujihara K, Kakita A, et al. Loss of aquaporin 4 in lesions of neuromyelitis optica: distinction from multiple sclerosis. Brain 2007;130: 1224-1234.

7. Lennon VA, Wingerchuk DM, Kryzer TJ, et al. A serum autoantibody marker of neuromyelitis optica: distinction from multiple sclerosis. Lancet 2004;364:2106-2112.

8. Lennon VA, Kryzer TJ, Pittock SJ, Verkman AS, Hinson SR. IgG marker of optic-spinal multiple sclerosis binds to the aquaporin-4 water channel. J Exp Med 2005;202:473-477.

9. Kinoshita M, Nakatsuji Y, Kimura T, et al. Neuromyelitis optica: passive transfer to rats by human immunoglobulin. Biochem Biophys Res Commun 2009;386:623-627.

10. Bradl M, Misu T, Takahashi T, et al. Neuromyelitis optica: pathogenicity of patient immunoglobulin in vivo. Ann Neurol 2009;66:630-643.

11. Sato D, Fujihara K. Neuromyelitis optica without typical opticospina phenotype. Mult Scler 2010;16:1154-1155.

12. Wingerchuk DM, Lennon VA, Pittock SJ, Lucchinetti CF, Weinshenker BG. Revised diagnostic criteria for neuromyelitis optica. Neurology 2006; 66:1485-1489.

13. Wingerchuk DM, Lennon VA, Lucchinetti CF, Pittock SJ, Weinshenker BG The spectrum of neuromyelitis optica. Lancet Neurol 2007;6:805-815.

14. Pittock SJ, Lennon VA, Krecke K, Wingerchuk DM, Lucchinetti CF, Weinshenker BG. Brain abnormalities in neuromyelitis optica. Arch Neurol 2006:63:390-396.

15. Kim W, Park MS, Lee SH, et al. Characteristic brain magnetic resonance imaging abnormalities in central nervous system aquaporin-4 autoimmunity. Mult Scler 2010;16:1229-1236.

16. Ito S, Mori M, Makino T, Hayakawa S, Kuwabara S. "Cloud-like enhancement" is a magnetic resonance imaging abnormality specific to neuromyelitis optica. Ann Neurol 2009;66:425-428.

17. Pittock SJ, Weinshenker BG, Lucchinetti CF, Wingerchuk DM, Corboy JR, Lennon VA. Neuromyelitis optica brain lesions localized at sites of high aquaporin 4 expression. Arch Neurol 2006;63:964-968.

18. Sato D, Takahashi T, Nakashima I, Misu T, Itoyama Y, Fujihara K. Aquaporin-4 antibody positive male patients: an analysis of 144 cases. Poster presented at the annual meeting of the American Academy of Neurology, Hawaii, HL 2011.

19. Misu T, Fujihara K, Nakashima I, Sato S, Itoyama Y. Intractable hiccup and nausea with periaqueductal lesions in neuromyelitis optica. Neurology 2005;65:1479-1482

20. Popescu BF, Lennon VA, Parisi JE, et al. Neuromyelitis optica unique area postrema lesions: nausea, vomiting, and pathogenic implications. Neurology 2011;76:1229-1237.

21. Takai Y, Nakashima I, Misu T, Fujihara K, Itoyama Y. Painful tonic spasm in neuromyelitis optica. Neurology 2010;74:A168-A169.

22. Baba T, Nakashima I, Kanbayashi T, et al. Narcolepsy as an initial manifestation of neuromyelitis optica with anti-aquaporin-4 antibody. J Neuro 2009:256:287-288.

23. Kanbayashi T, Shimohata T, Nakashima I, et al. Symptomatic narcolepsy in patients with neuromyelitis optica and multiple sclerosis: new neurochemical and immunological implications. Arch Neurol 2009;66: 1563-1566.

24. Suzuki N, Takahashi T, Aoki M, et al. Neuromyelitis optica preceded by hyperCKemia episode. Neurology 2010;74:1543-1545. 